\title{
Clinicopathological Features and Management of Cancers in Lynch Syndrome
}

\author{
Markku Aarnio \\ Department of Gastroenterological Surgery, Jyväskylä Central Hospital, 40620 Jyväskylä, Finland \\ Correspondence should be addressed to Markku Aarnio, markku.aarnio@ksshp.fi
}

Received 2 December 2011; Accepted 28 February 2012

Academic Editor: George L. Mutter

Copyright () 2012 Markku Aarnio. This is an open access article distributed under the Creative Commons Attribution License, which permits unrestricted use, distribution, and reproduction in any medium, provided the original work is properly cited.

Lynch syndrome (LS) is characterized by an autosomal dominant inheritance of the early onset of colorectal cancer (CRC) and endometrial cancer, as well as increased risk for several other cancers including gastric, urinary tract, ovarian, small bowel, biliary tract, and brain tumors. The syndrome is due to a mutation in one of the four DNA mismatch repair (MMR) genes $M L H 1, M S H 2$, MSH6, or PMS2. The majority of LS patients and families can now be identified, and the underlying mutation detected using genetic diagnostics. Regular surveillance for CRC and endometrial cancer has proved beneficial for mutation carriers. However, screening for other tumors is also recommended even though experiences in the screening of these tumors is limited. Prophylactic colectomy, prophylactic hysterectomy, and bilateral salpingo-oophorectomy may be reasonable options for selected patients with LS. This paper describes the features and management of LS.

\section{Introduction}

Lynch syndrome (LS), also referred to as hereditary nonpolyposis colorectal cancer (HNPCC), is the most common form of hereditary colorectal cancer, accounting for $2-5 \%$ of all colorectal cancer (CRC) cases $[1,2]$. The cancer predisposition in LS arises from germline mutations in any of the four DNA mismatch repair (MMR) genes MLH1, MSH2, MSH6, or PMS2 [3]. The mutation carriers are at high risk for developing CRC and endometrial cancer at a young age [4]. Many other tumor types such as gastric, ovarian, small bowel, urinary, and biliary tract, as well as brain tumors, have also been associated with LS $[5,6]$.

Clinical criteria, known as Amsterdam criteria I and II, have served to identify in LS families [7, 8]. Knowledge of the molecular genetic background of this syndrome has made it possible to develop molecular diagnostic methods, such as microsatellite instability (MSI) and immunohistochemical analysis, to identify cases with LS $[9,10]$. Identification of these high-risk individuals is necessary so that screening programs can be initiated to prevent the development of cancers. Screening for colorectal and endometrial cancers has proved beneficial for mutation carriers of LS [11, 12]. Obtaining more data on the features and behavior of different tumors associated with LS is also important in order to develop the management of these tumors.

This paper reviews the clinicopathological features, diagnostic criteria, and management of LS.

\section{Genetic Characteristics of Lynch Syndrome}

Mutations in four DNA mismatch repair (MMR) genes, MLH1, MSH2, PMS2, and MSH6, are known to cause susceptibility to LS [3]. The main function of MMR is to maintain genomic stability by correcting mismatches generated during DNA replication. MMR malfunction results in a mutator phenotype and microsatellite instability (MSI). In mutation carriers with Lynch syndrome, one mutation is present in each copy of the gene inherited via the germline and is therefore present in all cells. Only one other mutation (somatic) is required for the development of cancer. Approximately $95 \%$ of mutations reported so far in LS families have been the MLH1, MSH2, or MSH6 genes [13].

MSI is a hallmark of tumors in LS, but is also present in $15-25 \%$ of corresponding sporadic tumors [14]. Research has shown that the frequency of MSI is $60-100 \%$ in colorectal, endometrial, stomach, and uroepithelial cancers 
associated with LS [15-19]. MSI testing has therefore served as the diagnostic screening method for LS.

\section{Identification of Lynch Syndrome}

A family history of cancer plays an important role in the recognition of LS. Clinical criteria (Amsterdam I and II) have served in identifying LS families for clinical or research purposes [7, 8]. Amsterdam I criteria include the following: (1) at least three relatives should have histologically verified colorectal cancer, one of whom should be a first-degree relative to the other two; (2) at least two successive generations should be affected; (3) colorectal cancer should be diagnosed in one of the relatives under 50 years of age; (4) familial adenomatous polyposis should be excluded [6]. In 1999, the International Collaborative group on HNPCC introduced new selection criteria (Amsterdam criteria II) that also included extracolonic cancers associated with LS [8].

Clinical criteria known as the Bethesda Guidelines have been developed to enable identification of colorectal tumors in relation to which molecular analysis should be undertaken $[9,10]$. A patient who meets the Bethesda criteria may need for molecular genetic studies either by MSI analysis of the tumor or immunohistochemical analysis of the MMR proteins. If a mutation is identified in the family, genetic counselling and genetic testing should be organized for all at-risk relatives. Such testing allows clinical screening to focus on mutation carriers and to exclude noncarriers from repeated examinations.

\section{Tumor Spectrum of Lynch Syndrome}

$\mathrm{CRC}$ and endometrial cancer are the most prominent types of cancer seen in LS [4]. However, several other cancer types have been shown to occur more frequently in LS than in the general population: cancers of the stomach as well as urological (uroepithelial and kidney), ovary, biliary tract, small bowel, and brain tumors $[5,6]$. Researchers have suggested that cancer phenotypes associated with $M L H 1, M S H 2$, and MSH6 gene mutations differ. For example, Vasen et al. [20] found a higher risk for extracolonic cancers in mutation carriers of MSH2 than in those carriers of MLH1.

\section{Colorectal Cancer}

Colonic tumors are the most common tumors in LS, accounting for approximately $60-70 \%$ of the total $[21,22]$. Studies have reported that a lifetime risk for developing CRC in mutation carriers is $70 \%$ at age 70 (range $30-80 \%$ ) $[5,20$, 23]. However, the estimation of risk seems to differ depending on sex and type of mutation. A Finnish study [5] found that the standardized incidence ratio for CRC was higher in men (83) than in women (48), and the male-to-female ratio was 1.7. The reason for the relatively low incidence of CRC in women is unknown. Dunlop et al. [23] suggested that women may be protected in some way because of environmental factors or even a sex-linked modifier gene. There is no difference in CRC risk between MLH1 and MSH2 mutation carriers. However, Hendriks et al. [24] observed that female
MSH6 mutation carriers are at significantly lower risk for CRC than are $M L H 1$ and $M S H 2$ mutation carriers.

Several clinical features typical of colonic tumors are associated with this syndrome. They most often occur in the proximal colon $(60-70 \%$ in LS, $30 \%$ in sporadic CRC). CRC occurs at younger ages in HNPCC (mean $40-45$ years) than in sporadic cases (mean 60-65 years), and mutation carriers of HNPCC are at higher risk for multiple synchronous and metachronous CRCs [21, 22].

Colorectal tumors in LS seem to evolve through the adenoma-carcinoma sequence, as they do in sporadic CRC [25]. In Ls, however, the adenomas occur in younger individuals and tend to be larger and more severely dysplastic than in sporadic cases [26-29]. In addition, studies have shown that adenomas in LS patients are located mainly in the proximal colon $[29,30]$. Most adenomas in mutation carriers show MSI or the absence of immunohistochemical staining of the MMR proteins [31]. For CRC in LS, studies have reported MSI frequencies of $85-90 \%$ [16]. It has been suggested the that the adenoma-carcinoma sequence is accelerated in LS and that the progression from adenoma to carcinoma may take two to three years compared to eight to ten years in the general population [32]. Also, the histopathology of CRC in LS patients has some special features in comparison to CRC in general, as CRC is often mucinous and poorly differentiated $[26,27]$. Diploid tumors and singletring cancers also seem to be common in Lynch syndrome $[26,33]$; however, it should be noted that, although these features are not specific to this syndrome, they could serve as additional markers for its recognition.

Colonoscopic surveillance has been recommended for mutation carriers of LS to prevent the development of cancer. Järvinen et al. [11] conducted a long-term controlled study comparing colonoscopic screening (three-year intervals) with no screening of at-risk members of LS families. The results showed that screening significantly reduced the incidence of CRC ( $6 \%$ in screened patients versus $16 \%$ in controls) and in overall mortality ( $8 \%$ in screened patients versus $22 \%$ in controls). Recently, a group of European experts in hereditary gastrointestinal cancer recommended screening by colonoscopy for mutation carriers every one to two years beginning at age 20 to 25 [34].

As mentioned above, mutation carriers of LS are at relatively high risk for synchronous or metachronous tumors. Therefore, researchers have suggested that total or subtotal colectomy is the operation of choice in LS patients with colorectal tumors [35]. Others have discussed prophylactic colectomy as a reasonable option in mutation carriers for whom colonoscopy is painful or difficult $[36,37]$. In addition, prophylactic surgery may be the best treatment for a patient with several adenomas that cannot be removed endoscopically [36, 37]. Presently, however, prophylactic colectomy remains controversial in the management of LS patients. Recent studies have reported that patients with CRC from LS families survived longer than did sporadic CRC patients with same-stage tumors [38, 39]. The reasons for the favorable survival rate with CRC in this syndrome remain unclear. One explanation is that immunological host defense mechanisms may be more active in tumors of the MSI 
phenotype [40]. Also, it has been suggested that the relatively high mutational load that occurs in tumors with defective DNA repair systems is detrimental to their survival [41].

It has been suggested that nonsteroidal anti-inflammatory drugs (NSAID) (e.g., aspirin) reduce the risk for CRC $[42,43]$. Recently, Burn et al. [44] reported their results of the long-term effect of aspirin on the incidence of CRC in mutation carriers of LS. Their randomized study comprised 861 individuals with a mean follow-up time of 56 months. The authors showed that $600 \mathrm{mg}$ aspirin daily clearly reduced the incidence of cancer in carriers of LS after 56-month followup. The mechanisms by which aspirin prevents the development of cancer are unknown, though some have suggested that aspirin may be proapoptotic in the early stages of CRC development [44].

\section{Endometrial Cancer}

Endometrial cancer occurs at younger ages in LS patients than in sporadic cases. The mean age at diagnosis is 49 years compared to 60 years in the general population [45]. Studies have reported that families with MSH6 mutations are at higher risk for developing endometrial cancer (64-71\%) than MSH2 or MLH1 families (40-50\%) [24, 46]. As in the case of sporadic endometrial cancer, the majority of endometrial cancers in this syndrome are of the endometrial type [47]. Studies have shown that there is no difference in outcomes in endometrial cancer associated with LS compared to those in sporadic cancer [48].

Regular surveillance for endometrial cancer has been recommended for women with LS for the prevention or early diagnosis of cancer [34]. Some studies have investigated the efficacy of gynecological surveillance in LS. In a study by Dove-Edwin et al. [49], a study group consisted of 269 female LS family members in whom transvaginal ultrasound was performed every one to two years. No asymptomatic endometrial cancers were found, but two interval cancers were diagnosed based on symptoms. Rijcken et al. [50] presented the results of a gynecological screening program in 41 mutation carriers. They found three patients with premalignant lesions but no cases of asymptomatic endometrial cancer. A study of 175 mutation carriers from Finland reported the results of surveillance using transvaginal ultrasound and aspiration biopsy [12]. Endometrial cancer occurred in 14 cases, 11 of which were diagnosed using surveillance. Of the 11 screen-detected cancers, 6 were identified using only aspiration biopsy and not using ultrasound. The results also showed that stage distribution and survival were more favorable in the surveilled patients than in the unsurveilled patients. According to a study by Nieminen et al. [51], it seems that endometrial carcinoma will develop gradually via complex hyperplasia, and molecular genetics alternations can be observed years before cancer. Based on the previous studies $[12,49,50]$, current surveillance guidelines for women with LS include annual transvaginal ultrasound and endometrial sampling starting at age 20 to 35 years. Prophylactic hysterectomy and bilateral salpingo-oophorectomy are recommended for female mutation carriers who are beyond childbearing age, especially if surgery for colorectal cancer is needed [52].

\section{Gastric Cancer}

Gastric cancer is the second most common extracolonic malignancy in LS with a cumulative risk of $2 \%$ to $13 \%$ [5, 20, 53]. As in the case of colorectal and endometrial cancers, gastric cancer in this syndrome occurs at an earlier age than in the general population [54]. The occurrence of this carcinoma seems to be not different between different mutations.

Studies have shown that over $90 \%$ of gastric cancers in LS are of the intestinal type and that tumors have a high degree of MSI [54]. Generally, the diffuse type of cancer predominates in young patients and is the most common type in the familial form of gastric cancer [55]. The development of the intestinal type of gastric cancer is closely related to Helicobacter pylori-associated chronic gastritis. Studies have therefore suggested that $H$. pylori infection and atrophic gastritis could serve as markers of increased risk for gastric cancer in individuals with LS. A Finnish study, however, reported that only $20 \%$ of gastric cancers in LS were $H$. Pylori positive [54].

Renkonen-Sinisalo et al. [56] evaluated the value of gastroscopic surveillance in a series of 73 mutation carriers. In this study, no cases of early cancer or premalignant lesions were detected during surveillance. A collaborative group of European experts in hereditary gastrointestinal cancer recommends screening for gastric cancer in LS families with a clustering of stomach cancer and in countries with a high prevalence of it [34]. It has been suggested that serological biomarkers such as pepsinogen I and II as well as $H$. pylori antibodies, could be a nonendoscopic screening method in evaluating individual risk for gastric cancer in LS.

\section{Uroepithelial and Kidney Cancers}

Several epidemiological studies have shown that urothelial (i.e., ureter and bladder) as well as kidney cancers are an integral part of the LS tumor spectrum with a lifetime risk of $1 \%$ to $12 \%$ [5, 6, 53]. Van der Post et al. [57] reported a clearly increased risk for bladder cancer, especially in $\mathrm{MSH} 2$ mutation carriers. Correspondingly, Watson et al. [6] found that $\mathrm{MSH} 2$ mutation carriers were at a sevenfold higher lifetime risk for urological tumors than were $M L H 1$ mutation carriers. Ureter and bladder cancers occur approximately 10 15 years earlier than those in the general population $[6,57]$. The histology of these urothelial tumors associated with LS is similar to that of sporadic cases [57]. Studies have reported high frequencies of MSI for urothelial tumors in LS that clearly exceed frequencies for corresponding sporadic tumors [19].

A higher risk for kidney adenocarcinomas has been observed in a large series of LS families than in the general population $[5,6]$. MSI is seldom observed in kidney cancers, however, and the median age of this cancer seems to be not lower than that in sporadic cases [19]. Therefore, researchers have suggested that kidney cancers may not be part of the tumor spectrum of LS. 
Urine cytology has been shown to be insensitive in screening for bladder and ureter cancers in LS mutation carriers [58]. On the other hand, European experts in hereditary gastrointestinal cancer recommend screening for urological tumors using abdominal ultrasound, urinalysis, and urine cytology [34]. Screening should start at age 30 to 35 years with one- to two-year intervals [34]. This strategy is especially intended for families with clustering urological tumors [34].

\section{Other Tumors}

9.1. Ovarian Cancer. Ovarian cancer has been shown to occur in excess in LS. Two Finnish studies $[5,45]$ have shown a lifetime risk for ovarian cancer in LS ranging between $9 \%$ and $12 \%$ compared to $1.3 \%$ in the general population. Recently, Watson et al. [6] reported a lifetime risk of 7\% in a large series from four LS research centers. They also found that $\mathrm{MSH} 2$ family members had nearly twice the incidence rate observed in MLH1 family members, and the highest risk period for ovarian cancer was from age 40 to 55 years. Ovarian cancer in LS seems to have a better prognosis than that in the general population or in BRCA1/2 mutation carriers [59]. Information currently available is too limited to assess whether screening for ovarian cancer in LS mutation carriers has any advantages.

9.2. Carcinomas of the Biliary Tract and Pancreas. These carcinomas seem to be associated with LS [60]. Estimates indicate that a lifetime risk of these cancers is approximately $2 \%$ in mutation carriers of LS $[5,45]$. Surveillance for pancreatic or biliary tract cancer is not regularly recommended for family members with LS.

The lifetime risk for small bowel cancer associated with LS has been estimated to range between $1 \%$ and $4 \%[20,61]$. Studies have also reported that LS-associated small bowel cancer often manifests at a young age and may be the first disease manifestation $[61,62]$. Tumors occur predominantly in the duodenum or the jejunum $[61,62]$. Screening for small bowel cancer is not in the guidelines for clinical management of family members with LS.

9.3. Brain Tumors. Brain tumors occur in excess in patients with LS [63]. The estimated cumulative incidence of brain tumor ranges from $2 \%$ to $4 \%$ in family members with LS $[5,6]$. Vasen et al. [53] reported that the risk for brain tumor is higher in $M S H 2$ than in MLH1 mutation carriers. It has also been reported that brain tumors in LS are microsatellite stable [19]. No studies have investigated surveillance for brain tumors in LS.

\section{Conclusions}

Knowledge of the tumor spectrum in Lynch syndrome is important in planning strategies for the management of patients with this syndrome. Screening proved beneficial only for CRC and endometrial cancer although screening for other tumors is also recommended. Family history is an important tool for identifying LS. Clinical criteria serve to select suspected cases for molecular studies, such as MSI analysis of the tumors or immunohistochemical analysis of the MMR proteins. It is now possible to undertake predictive genetic testing in family members once a mutation has been detected in a family. However, it is important to organize genetic counselling individually before genetic testing. Genetic testing allows clinical screening to target mutation carriers while excluding mutation-negative individuals from further examination.

\section{Acknowledgments}

This study was supported by grants from the Jyväskylä Central Hospital. The author is grateful to Professor Päivi Peltomäki for constructive comments for the paper.

\section{References}

[1] L. Aaltonen, L. Johns, H. Järvinen, J. P. Mecklin, and R. Houlston, "Explaining the familial colorectal cancer risk associated with mismatch repair (MMR)-deficient and MMRstable tumors," Clinical Cancer Research, vol. 13, no. 1, pp. 356-361, 2007.

[2] H. T. Lynch and A. de la Chapelle, "Hereditary colorectal cancer," New England Journal of Medicine, vol. 348, no. 10, pp. 919-932, 2003.

[3] W. M. Abdel-Rahman, J. P. Mecklin, and P. Peltomaki, "The genetics of HNPCC: application to diagnosis and screening," Critical Reviews in Oncology / Hematology, vol. 58, no. 3, pp. 208-220, 2006.

[4] H. T. Lynch and T. Smyrk, "Hereditary nonpolyposis colorectal cancer (Lynch syndrome). An updated review," Cancer, vol. 78, no. 6, pp. 1149-1167, 1996.

[5] M. Aarnio, R. Sankila, E. Pukkala et al., "Cancer risk in mutation carriers of DNA-mismatch-repair genes," International Journal of Cancer, vol. 81, no. 2, pp. 214-218, 1999.

[6] P. Watson, H. F. A. Vasen, J. P. Mecklin et al., "The risk of extracolonic, extra-endometrial cancer in the Lynch syndrome," International Journal of Cancer, vol. 123, no. 2, pp. 444-449, 2008.

[7] H. F. A. Vasen, J. P. Mecklin, P. Meera Khan, and H. T. Lynch, "The international collaborative group on hereditary nonpolyposis colorectal cancer (ICG-HNPCC)," Diseases of the Colon and Rectum, vol. 34, no. 5, pp. 424-425, 1991.

[8] H. F. A. Vasen, P. Watson, J. P. Mecklin, and H. T. Lynch, "New clinical criteria for hereditary nonpolyposis colorectal cancer (HNPCC, Lynch syndrome) proposed by the International Collaborative Group on HNPCC," Gastroenterology, vol. 116, no. 6, pp. 1453-1456, 1999.

[9] M. A. Rodriguez-Bigas, C. R. Boland, S. R. Hamilton et al., "A national cancer institute workshop on hereditary nonpolyposis colorectal cancer syndrome: meeting highlights and Bethesda guidelines," Journal of the National Cancer Institute, vol. 89, no. 23, pp. 1758-1762, 1997.

[10] A. Umar, C. R. Boland, J. P. Terdiman et al., "Revised Bethesda guidelines for hereditary nonpolyposis colorectal cancer (Lynch syndrome) and microsatellite instability," Journal of the National Cancer Institute, vol. 96, no. 4, pp. 261-268, 2004.

[11] H. J. Järvinen, M. Aarnio, H. Mustonen et al., "Controlled 15year trial on screening for colorectal cancer in families with hereditary nonpolyposis colorectal cancer," Gastroenterology, vol. 118 , no. 5, pp. 829-834, 2000. 
[12] R.-S. Laura, R. Butzow, A. Leminen, P. lehtovirtsa, J. P. Mecklin, and H. J. Järvinen, "Surveillance for endometrial cancer in hereditary nonplyposis colorectal cancer syndrome," International Journal of Cancer, vol. 120, no. 4, pp. 821-824, 2006.

[13] P. Peltomäki and H. Vasen, "Mutations associated with HNPCC predisposition-update of ICG-HNPCC/INSiGHT mutation database," Disease Markers, vol. 20, no. 4-5, pp. 269 276, 2004.

[14] P. Peltomäki, "Role of DNA mismatch repair defects in the pathogenesis of human cancer," Journal of Clinical Oncology, vol. 21, no. 6, pp. 1174-1179, 2003.

[15] L. A. Aaltonen, P. Peltomaki, F. S. Leach et al., "Clues to the pathogenesis of familial colorectal cancer," Science, vol. 260, no. 5109, pp. 812-816, 1993.

[16] L. A. Aaltonen, P. Peltomaki, J. P. Mecklin et al., "Replication errors in benign and malignant tumors from hereditary nonpolyposis colorectal cancer patients," Cancer Research, vol. 54, no. 7, pp. 1645-1648, 1994.

[17] M. van den Bos, M. Van Den Hoven, E. Jongejan et al., "More differences between HNPCC-related and sporadic carcinomas from the endometrium as compared to the colon," American Journal of Surgical Pathology, vol. 28, no. 6, pp. 706-711, 2004.

[18] A. Gylling, W. M. Abdel-Rahman, M. Juhola et al., "Is gastric cancer part of the tumour spectrum of hereditary non-polyposis colorectal cancer? a molecular genetic study," Gut, vol. 56, no. 7, pp. 926-933, 2007.

[19] A. H. S. Gylling, T. T. Nieminen, W. M. Abdel-Rahman et al., "Differential cancer predisposition in Lynch syndrome: insights from molecular analysis of brain and urinary tract tumors," Carcinogenesis, vol. 29, no. 7, pp. 1351-1359, 2008.

[20] H. F. A. Vasen, J. T. Wijnen, F. H. Menko et al., "Cancer risk in families with hereditary nonpolyposis colorectal cancer diagnosed by mutation analysis," Gastroenterology, vol. 110, no. 4, pp. 1020-1027, 1996.

[21] J. P. Mecklin and H. J. Jarvinen, "Clinical features of colorectal carcinoma in cancer family syndrome," Diseases of the Colon and Rectum, vol. 29, no. 3, pp. 160-164, 1986.

[22] H. F. A. Vasen, G. J. A. Offerhaus, F. C. A. Den Hartog Jager et al., "The tumour spectrum in hereditary non-polyposis colorectal cancer: a study of 24 kindreds in The Netherlands," International Journal of Cancer, vol. 46, no. 1, pp. 31-34, 1990.

[23] M. G. Dunlop, S. M. Farrington, A. D. Carothers et al., "Cancer risk associated with germline DNA mismatch repair gene mutations," Human Molecular Genetics, vol. 6, no. 1, pp. 105-110, 1997.

[24] Y. M. C. Hendriks, A. Wagner, H. Morreau et al., "Cancer risk in hereditary nonpolyposis colorectal cancer due to MSH6 mutations: impact on counseling and surveillance," Gastroenterology, vol. 127, no. 1, pp. 17-25, 2004.

[25] J.-P. Mecklin, M. Aarnio, E. Läärä et al., "Development of colorectal tumors in colonoscopic surveillance in Lynch Syndrome," Gastroenterology, vol. 133, no. 4, pp. 1093-1098, 2007.

[26] J. P. Mecklin, P. Sipponen, and H. J. Jarvinen, "Histopathology of colorectal carcinomas and adenomas in cancer family syndrome," Diseases of the Colon and Rectum, vol. 29, no. 12, pp. 849-853, 1986.

[27] H. T. Lynch, T. C. Smyrk, P. Watson et al., "Genetics, natural history, tumor spectrum, and pathology of hereditary nonpolyposis colorectal cancer: an updated review," Gastroenterology, vol. 104, no. 5, pp. 1535-1549, 1993.

[28] J. R. Jass, "Colorectal adenomas in surgical specimens from subjects with hereditary non-polyposis colorectal cancer," Histopathology, vol. 27, no. 3, pp. 263-267, 1995.
[29] S. J. Lanspa, H. T. Lynch, T. C. Smyrk et al., "Colorectal adenomas in the Lynch syndromes: results of a colonoscopy screening program," Gastroenterology, vol. 98, no. 5, pp. 1117-1122, 1990.

[30] P. Gaglia, W. S. Atkin, S. Whitelaw et al., "Variables associated with the risk of colorectal adenomas in asymptomatic patients with a family history of colorectal cancer," Gut, vol. 36, no. 3, pp. 385-390, 1995.

[31] A. E. de Jong, H. Morreau, M. Van Puijenbroek et al., "The role of mismatch repair gene defects in the development of adenomas in patients with HNPCC," Gastroenterology, vol. 126, no. 1, pp. 42-48, 2004.

[32] H. F. A. Vasen, F. M. Nagengast, and P. Meera Khan, "Interval cancers in hereditary non-polyposis colorectal cancer (Lynch syndrome)," The Lancet, vol. 345, no. 8958, pp. 1183-1184, 1995.

[33] M. Kouri, A. Laasonen, J. P. Mecklin, H. Jarvinen, K. Franssila, and S. Pyrhonen, "Diploid predominance in hereditary nonpolyposis colorectal carcinoma evaluated by flow cytometry," Cancer, vol. 65, no. 8, pp. 1825-1829, 1990.

[34] H. F. A. Vasen, G. Möslein, A. Alonso et al., "Guidelines for the clinical management of Lynch syndrome (hereditary nonpolyposis cancer)," Journal of Medical Genetics, vol. 44, no. 6, pp. 353-362, 2007.

[35] N. Natarajan, P. Watson, E. Silva-Lopez, and H. T. Lynch, "Comparison of extended colectomy and limited resection in patients with lynch syndrome," Diseases of the Colon and Rectum, vol. 53, no. 1, pp. 77-82, 2010.

[36] J. M. Church, "Prophylactic colectomy in patients with hereditary nonpolyposis colorectal cancer," Annals of Medicine, vol. 28, no. 6, pp. 479-482, 1996.

[37] H. J. Järvinen and M. Aarnio, "Surveillance on mutation carriers of DNA mismatch repair genes," Annales Chirurgiae et Gynaecologiae, vol. 89, no. 3, pp. 207-210, 2000.

[38] R. Sankila, L. A. Aaltonen, H. J. Jarvinen, and J. P. Mecklin, "Better survival rates in patients with MLH1-associated hereditary colorectal cancer," Gastroenterology, vol. 110, no. 3, pp. 682-687, 1996.

[39] P. Watson, K. M. Lin, M. A. Rodriquez-Bigas, T. Smyrk, S. Lemon, and M. Shadhisharan, "Colorectal carcinoma survival among hereditary nonpolyposis colorectal carcinoma family members," Cancer, vol. 83, no. 2, pp. 259-266, 1998.

[40] H. Kim, J. Jen, B. Vogelstein, and S. R. Hamilton, "Clinical and pathological characteristics of sporadic colorectal carcinomas with DNA replication errors in microsatellite sequences," American Journal of Pathology, vol. 145, no. 1, pp. 148-156, 1994.

[41] D. Shibata, M. A. Peinado, Y. Ionov, S. Malkhosyan, and M. Perucho, "Genomic instability in repeated sequences is an early somatic event in colorectal tumorigenesis that persists after transformation," Nature Genetics, vol. 6, no. 3, pp. 273281, 1994.

[42] E. Flossmann and P. M. Rothwell, "Effect of aspirin on longterm risk of colorectal cancer: consistent evidence from randomised and observational studies," The Lancet, vol. 369, no. 9573, pp. 1603-1613, 2007.

[43] J. Cuzick, F. Otto, J. A. Baron et al., "Aspirin and non-steroidal anti-inflammatory drugs for cancer prevention: an international consensus statement," The Lancet Oncology, vol. 10, no. 5, pp. 501-507, 2009.

[44] J. Burn, A.-M. Gerdes, F. Macrae et al., "Long-term effect of aspirin on cancer risk in carriers of hereditary colorectal cancer: an analysis from the CAPP2 randomised controlled study," The Lancet, vol. 378, no. 9809, pp. 2081-2087, 2011. 
[45] M. Aarnio, J. P. Mecklin, L. A. Aaltonen, M. Nystrom-Lahti, and H. J. Jarvinen, "Life-time risk of different cancers in hereditary non-polyposis colorectal cancer (HNPCC) syndrome," International Journal of Cancer, vol. 64, no. 6, pp. 430-433, 1995.

[46] M. G. Dunlop, S. M. Farrington, A. D. Carothers et al., "Cancer risk associated with germline DNA mismatch repair gene mutations," Human Molecular Genetics, vol. 6, no. 1, pp. 105110, 1997.

[47] R. R. Broaddus, H. T. Lynch, L. M. Chen et al., "Pathologic features of endometrial carcinoma associated with HNPCC: a comparison with sporadic endometrial carcinoma," Cancer, vol. 106, no. 1, pp. 87-94, 2006.

[48] D. E. S. Boks, A. P. Trujillo, A. C. Voogd, H. Morreau, G. G. Kenter, and H. F. A. Vasen, "Survival analysis of endometrial carcinoma associated with hereditary nonpolyposis colorectal cancer," International Journal of Cancer, vol. 102, no. 2, pp. 198-200, 2002.

[49] I. Dove-Edwin, D. Boks, S. Goff et al., "The outcome of endometrial carcinoma surveillance by ultrasound scan in women at risk of hereditary nonpolyposis colorectal carcinoma and familial colorectal carcinoma," Cancer, vol. 94, no. 6, pp. 1708-1712, 2002.

[50] F. E. Rijcken, M. J. Mourits, J. H. Kleibeuker, H. Hollema, and A. G. van der Zee, "Gynekologic screening in hereditary nonpolyposis colorectal cancer," Gynecologic Oncology, vol. 91, no. 1 , pp. 74-80, 2003.

[51] T. T. Nieminen, A. Gylling, W. M. Abdel-Rahman et al., "Molecular analysis of endometrial tumorigenesis: importance of complex hyperplasia regardless of atypia," Clinical Cancer Research, vol. 15, no. 18, pp. 5772-5783, 2009.

[52] J. J. Koornstra, M. J. Mourits, R. H. Sijmons, A. M. Leliveld, H. Hollema, and J. H. Kleibeuker, "Management of extracolonic tumours in patients with Lynch syndrome," The Lancet Oncology, vol. 10, no. 4, pp. 400-408, 2009.

[53] H. F. A. Vasen, A. Stormorken, F. H. Menko et al., "MSH2 mutation carriers are at higher risk of cancer than MLH1 mutation carriers: a study of hereditary nonpolyposis colorectal cancer families," Journal of Clinical Oncology, vol. 19, no. 20, pp. 4074-4080, 2001.

[54] M. Aarnio, R. Salovaara, L. A. Aaltonen, J. P. Mecklin, and H. J. Järvinen, "Features of gastric cancers in hereditary nonpolyposis colorectal cancer syndrome," International Journal of Cancer, vol. 74, pp. 551-555, 1997.

[55] J. Lehtola, "Family study of gastric carcinoma: with special reference to histological types," Scandinavian Journal of Gastroenterology, vol. 13, supplement 50, pp. 1-54, 1978.

[56] L. Renkonen-Sinisalo, P. Sipponen, M. Aarnio et al., "No support for endoscopic surveillance for gastric cancer in hereditary non-polyposis colorectal cancer," Scandinavian Journal of Gastroenterology, vol. 37, no. 5, pp. 574-577, 2002.

[57] R. S. van der Post, L. A. Kiemeney, M. J. L. Ligtenberg et al., "Risk of urothelial bladder cancer in Lynch syndrome is increased, in particular among MSH2 mutation carriers," Journal of Medical Genetics, vol. 47, no. 7, pp. 464-470, 2010.

[58] T. Myrhoj, M. B. Andersen, and I. Bernstein, "Screening for urinary tract cancer with urine cytology in Lynch syndrome and familial colorectal cancer," Familial Cancer, vol. 7, no. 4, pp. 303-307, 2008.

[59] E. M. Grindedal, L. Renkonen-Sinisalo, H. Vasen et al., "Survival in women with MMR mutations and ovarian cancer: a multicentre study in Lynch syndrome kindreds," Journal of Medical Genetics, vol. 47, no. 2, pp. 99-102, 2010.
[60] J. P. Mecklin, H. J. Jarvinen, and M. Virolainen, “The association between cholangiocarcinoma and hereditary nonpolyposis colorectal carcinoma," Cancer, vol. 69, no. 5, pp. 11121114, 1992.

[61] K. Schulmann, F. E. Brasch, E. Kunstmann et al., "HNPCCassociated small bowel cancer: clinical and molecular characteristics," Gastroenterology, vol. 128, no. 3, pp. 590-599, 2005.

[62] M. A. Rodriquez-Bigas, H. F. A. Vasen, H. T. Lynch et al., "Characteristics of small bowel carcinoma in hereditary nonpolyposis colorectal carcinoma," Cancer, vol. 83, no. 2, pp. 240-244, 1998.

[63] H. F. A. Vasen, E. A. C. M. Sanders, B. G. Taal et al., "The risk of brain tumours in hereditary non-polyposis colorectal cancer (HNPCC)," International Journal of Cancer, vol. 65, no. 4, pp. 422-425, 1996. 


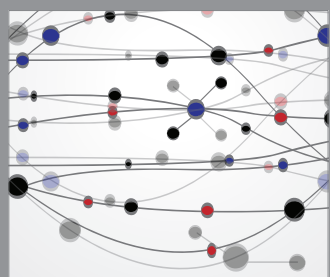

The Scientific World Journal
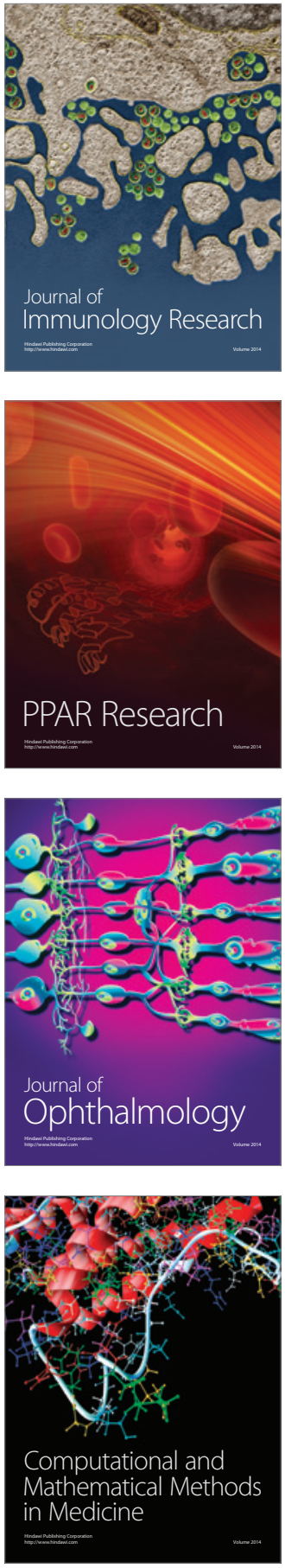

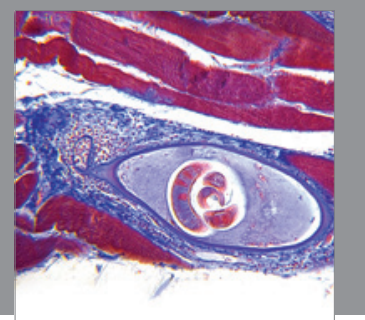

Gastroenterology

Research and Practice
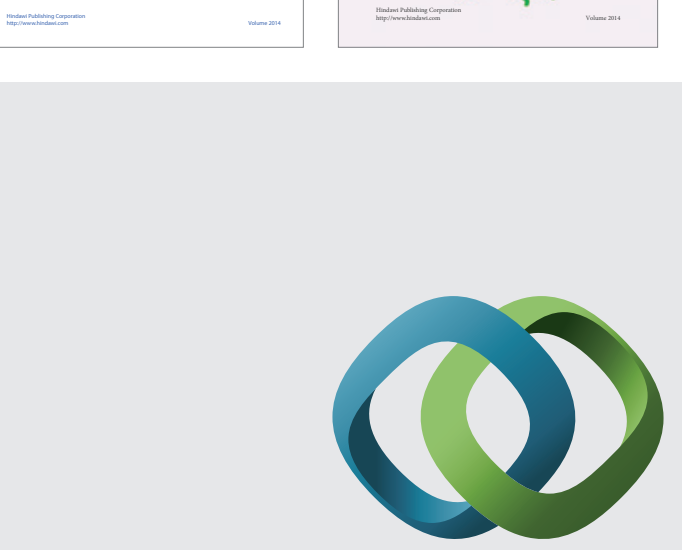

\section{Hindawi}

Submit your manuscripts at

http://www.hindawi.com
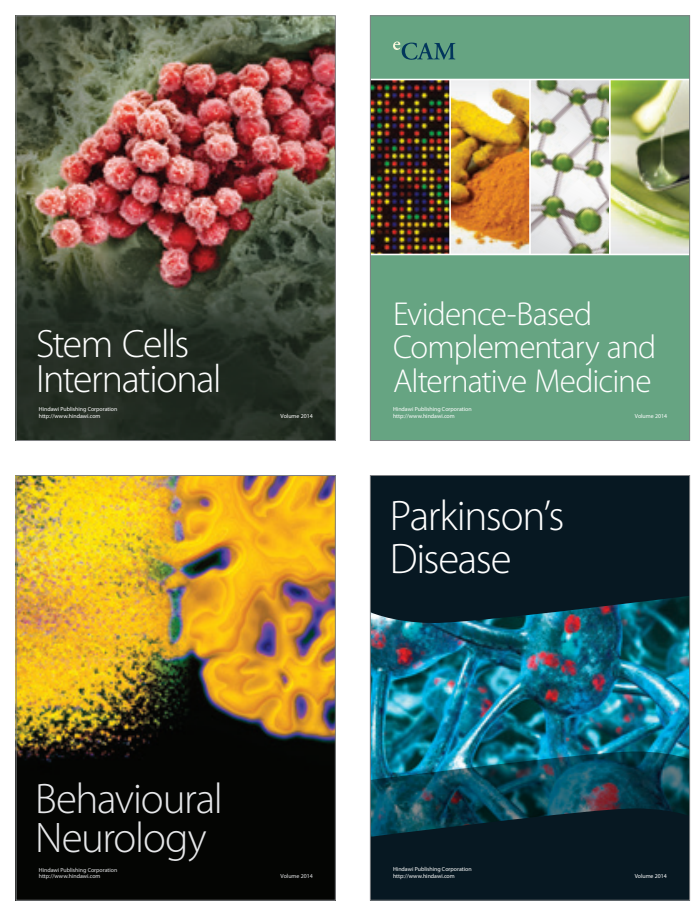

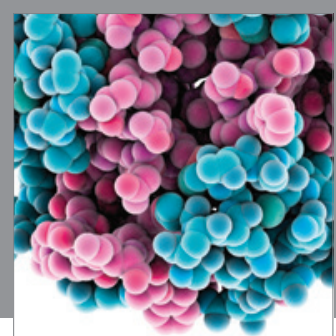

Journal of
Diabetes Research

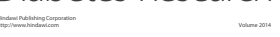

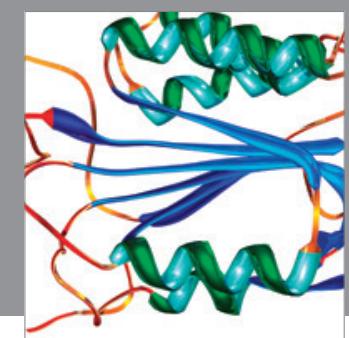

Disease Markers
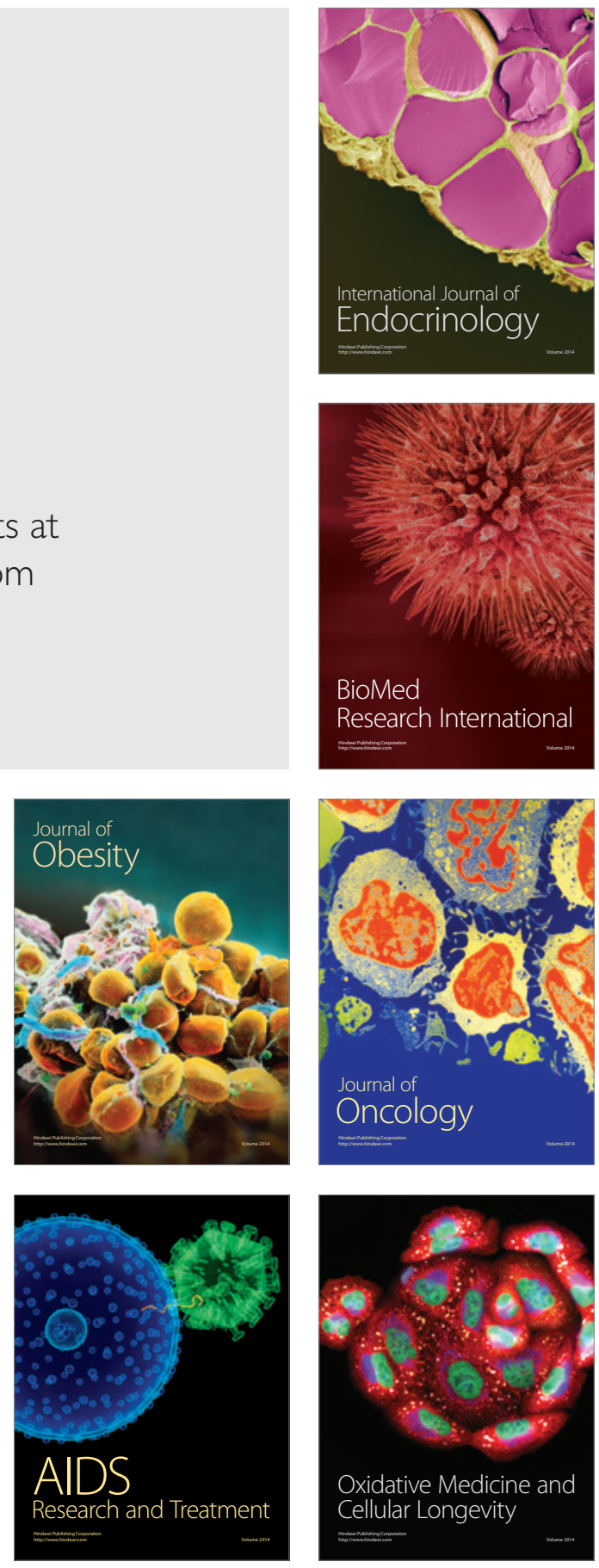